\title{
Pelatihan Skrining Penyakit Tidak Menular dan Pencegahannya Bagi Kader Kesehatan
}

\author{
Tri Wulandari Kesetyaningsih ${ }^{*}$, Suryanto ${ }^{1}$, Yoni Astuti ${ }^{1}$, \\ ${ }^{1}$ Pendidikan Dokter, Fakultas Kedokteran dan Ilmu Kesehatan, Universitas Muhammadiyah \\ Yogyakarta \\ Email: $\underline{\text { tri_wulandari@umy.ac.id, 2suryapatklin@umy.ac.id, 3yoniastuti@umy.ac.id }}$
}

\begin{abstract}
Abstrak
Pelatihan skrining bertujuan memberikan keterampilan menentukan kondisi kesehatan seseorang berdasarkan indeks massa tubuh (IMT) dan pemeriksaan darah sederhana. Kader kesehatan yang telah dibekali keterampilan menentukan IMT dan pemeriksaan darah sederhana, selanjutnya dapat mendeteksi dini PTM di masyarakat secara mandiri. Pelatihan gizi bertujuan untuk memberikan keterampilan menghitung kecukupan gizi dari menu sehari. Video edukasi cara pemeriksaan darah sederhana dibuat untuk menggantikan pelatihan praktek langsung karena keterbatasan protokol covid19. Sebelum dan sesudah pelatihan dilakukan pre dan pos test. Pelatihan diikuti oleh 15 peserta kader kesehatan di Pedukuhan Gamping Kidul, Ambarketawang, Gamping, Sleman, Yogyakarta. Nilai rata-rata sebelum pelatihan sebesar 67,14 naik menjadi 73,57 setelahnya. Analisis paired T-test menunjukkan tidak ada perbedaan bermakna skor pre dan post $(p=0,076)$. Setelah mendapatkan pelatihan, diharapkan kader kesehatan dapat melakukan skrining secara mandiri di lingkungan Posyandunya masing-masing, sehingga deteksi dini penyakit tidak menular (PTM) di masyarakat dapat berjalan, selanjutnya dapat dilakukan pencegahan agar tidak menjadi komplikasi. Disimpulkan bahwa pelatihan dapat meningkatkan pemahaman kader kesehatan tentang skrining PTM, pencegahan dan menghitung menu bergizi seimbang tetapi tidak signifikan.
\end{abstract}

Kata Kunci: penyakit tidak menular, skrining, pelatihan kader, pencegahan

\section{Abstract}

Non-communicable disease (NCD) screening training aims to provide skills in determining a person's health condition based on body mass index (BMI) and simple blood tests. Health cadres who have been equipped with the skills to determine BMI and simple blood tests can then detect NCD in the community independently. Nutrition training aims to provide skills in calculating nutritional adequacy from a daily menu. Educational videos on simple blood tests were made to replace hands-on training due to limitations of the covid19 protocol. Before and after training, pre and posttest were carried out. The training was attended by 15 health caddre participants in Gamping Kidul Village, Ambarketawang, Gamping, Sleman, Yogyakarta. The average score before training was 67.14, increasing to 73.57 thereafter. Paired T-test analysis showed no significant difference in pre and posttest scores $(p=0.076)$. After receiving the training, it is hoped that health cadres can carry out screening independently around their respective homes, so that early detection of NCD in the community can take place, then prevention can be carried out so that it does not become a fatal complication. It was concluded that the training could improve health cadres' understanding of PTM screening, prevention and calculating a balanced nutritious diet but not significant.

Keywords: non communicable disease, screening, cadres training, prevention 


\section{PENDAHULUAN}

Di Indonesia saat ini terjadi peningkatan angka kejadian penyakit degeneratif (penyakit tidak menular/ PTM), yaitu penyakit kronis akibat berkurangnya fungsi organ tubuh. Proses degeratif sebenarnya merupakan proses alamiah yang terjadi pada usia lanjut yang diakibatkan oleh menurunnya fungsi fisiologis tubuh. Pada umumnya fungsi fisiologis tubuh akan menurun setelah berumur 40 tahun (McPhee et al, 2016), namun angka kejadian penyakit degeneratif pada usia produktif semakin tinggi. Hal ini akibat pola hidup yang buruk (Cozma et al, 2018; Michishita et al, 2016), seperti aktivitas fisik kurang, pola makan buruk, salah menyikapi masalah hidup dan lingkungan kurang sehat (Cozma et al, 2018). Termasuk PTM antara lain adalah hipertensi dan diabetes mellitus yang dapat menyebabkan komplikasi seperti gagal jantung, gagal ginjal dan stroke.

Sejak tahun 1992 pemerintah Indonesia telah merubah paradigma kesehatan, dari berorientasi pada sakit ke sehat. Paradigma sakit selalu berpikir dan berperilaku bagaimana mengobati orang sakit (kuratif), sedangkan paradigma sehat selalu berpikir bagaimana hidup secara sehat dan mencegah sakit. Sekarang banyak orang yang sudah melakukan dan mempromosikan agar selalu mengedepankan pencegahan daripada mengobati, namun demikian angka kejadian PTM masih tinggi di Indonesia. Menurut WHO (2018), PTM di Indonesia menyebabkan $73 \%$ dari seluruh kematian sebesar 1.863.000 tahun 2016 dari total populasi sebesar 261.100.000. Di Provinsi DIY, PTM yaitu hipertensi dan DM tipe 2 termasuk 10 besar penyakit yang paling banyak diderita masyarakat (Dinkes DIY, 2020). Hal ini menandakan bahwa upaya menurunkan angka kejadian PTM yang efektif masih menjadi tantangan.

Kecamatan Gamping termasuk wilayah aglomerasi perkotaan Yogyakarta, yang berkembang pesat menjadi pusat pendidikan, terutama pendidikan tinggi. Terdapat beberapa perguruan tinggi berlokasi di sekitar Kecamatan Gamping. Kondisi ini berdampak pada gaya hidup masyarakat di sekitar kampus. Mereka disibukkan dengan melakukan bisnis terkait dengan pelayanan mahasiswa penghuni kost. Kesibukan baru ini berakibat pada semakin sedikitnya waktu untuk istirahat, berolah raga dan meningkatkan stress. Pola hidup yang tidak baik dapat meningkatkan risiko terkena PTM. Upaya yang telah dilakukan pemerintah selama ini berupa penyuluhan kesehatan, namun belum ada kegiatan yang langsung menyentuh di masyarakat untuk menerapkan pola hidup sehat sehingga diperlukan upaya agar program penerapan gaya hidup sehat dapat benar-benar telah berjalan dan efektif menurunkan PTM di masyarakat.

Kegiatan PKM ini berupaya agar penerapan pola hidup sehat dapat berjalan efektif di masyarakat. Kegiatan PKM sebelumnya telah membentuk grup senam dan senam rutin dua kali seminggu. Kegiatan dilanjutkan dengan pelatihan skrining PTM melalui pemeriksaan darah sederhana dan menentukan indeks massa tubuh (IMT), serta menghitung kecukupan gizi dari menu sehari-hari untuk kader kesehatan. Diharapkan kader dapat melakukan skrining PTM di Posyandu kemudian hasilnya dapat dilaporkan ke Puskesmas sehingga dapat ditindak lanjuti segera oleh Pemerintah untuk mencegah menjadi komplikasi. Kader juga dapat menerapkan penyediaan makanan bergizi seimbang bagi keluarga dan menularkannya kepada masyarakat.

\section{METODE PELAKSANAAN}

Kegiatan pengabdian diawali dengan melakukan koordinasi dengan ketua PKK sebagai mitra. Mitra menunjuk beberapa kader kesehatan yang mewakili beberapa RT di Dusun lokasi pengabdian. Jumlah kader sebanyak 15 orang mengingat masa pandemi mengharuskan pertemuan terbatas dengan protokol covid yang disiplin. Pelatihan dilaksanakan di luar ruangan dan selama pelatihan peserta wajib menggunakan masker, menggunakan face shield, hand sanitizer dan menjaga jarak. Pengabdi menyediakan masker, face shield dan hand sanitizer secara gratis.

Metode pengabdian mengalami perubahan karena pandemi covid-19. Dari beberapa kali pertemuan yang direncanakan, hanya dilakukan sekali pertemuan dengan durasi waktu maksimal 2 jam. Pelatihan mengenai pemeriksaan darah sederhana yang semula dilakukan praktek, tidak dapat dilaksanakan. Sebagai gantinya, tim pengabdian membuat video yang kemudian 
diputar pada saat pelatihan. Materi tentang kecukupan gizi juga dilakukan secara demo menghitung nilai gizi dari contoh menu sehari yang sudah dibawa oleh peserta. Materi tentang IMT juga dilakukan secara demo, bukan praktek karena keterbatasan waktu. Susunan acara pelatihan adalah: pretest, skrining PTM dengan menentukan IMT, pemeriksaan darah sederhana, menentukan kecukupan gizi dari contoh menu sehari dan postest.

Alat dan bahan yang digunakan: pengukur tinggi badan dan berat badan untuk menentukan IMT, dan alat tulis untuk mencatat IMT. Komputer, LCD dan layar untuk pemutaran video. Timbangan elektrik untuk menghitung kecukupan gizi dan contoh makanan yang dihitung nilai gizinya. Data dikumpulkan dari kuesioner mengenai pertanyaan tentang materi pelatihan. Data skor pengetahuan sebelum pelatihan dan sesudahnya dianalisis menggunakan paired $\mathrm{T}$ test untuk menentukan signifikansi perbedaan skor pengetahuan antara sebelum dan sesudah pelatihan

\section{HASIL DAN PEMBAHASAN}

Pengabdian dimulai dengan sosialisasi program dan perekrutan peserta yang bersedia untuk menjadi peserta pelatihan. Karena kondisi pandemi covid-19, pelatihan hanya diikuti oleh 15 orang kader kesehatan di Dusun Gamping Kidul, Ambarketawang, Gamping, Sleman. Pelaksanaan kegiatan di teras Masjid Assalam, untuk menetapi protokol covid-19.

Pelatihan terdiri dari tiga tahap yaitu pemutaran video tentang pemeriksaan darah sederhana untuk skrining PTM yang diikuti dengan penjelasan dan diskusi, praktek menghitung BMI untuk menentukan status Gizi seseorang, dan demonstrasi menghitung kecukupan gizi dari menu sehari yang telah dibawa oleh peserta.

Pandemi Covid-19 mengharuskan untuk tidak melakukan pertemuan yang lama dan intens, sehingga pelatihan dilakukan lebih singkat dan tidak ada praktek pengambilan darah secara langsung. Dokumentasi kegiatan disajikan pada Gambar 1-5. Sebelum dilakukan kegiatan para peserta diberikan penjelasan mengenai pentingnya pencegahan Covid-19 dengan menggunakan masker, mencuci tangan atau menggunakan hand sanitizer dan menjaga jarak (Gambar 1). Sebelum dan sesudah pelaksanaan pengabdian dilakukan pengukuran dengan mengerjakan pretest dan postest mengenai skrining PTM dan menu gizi seimbang (Gambar 2). Pemutaran video pemeriksaan daah sederhana untuk skrining PTM yang diperankan oleh aanggota pengabdi dr. Suryanto, SpPK dan seorang probandus (Gambar 3), dilanjutkan dengan penentuan BMI dan menghitung kecukupan gizi (Gambar 4,5). Pada Gambar 5 tampak bahwa bagian kanan adalah menu yang sudah mencukupi kebutuhan gizi, sedangkan bagian kiri merupakan kelebihan gizi.

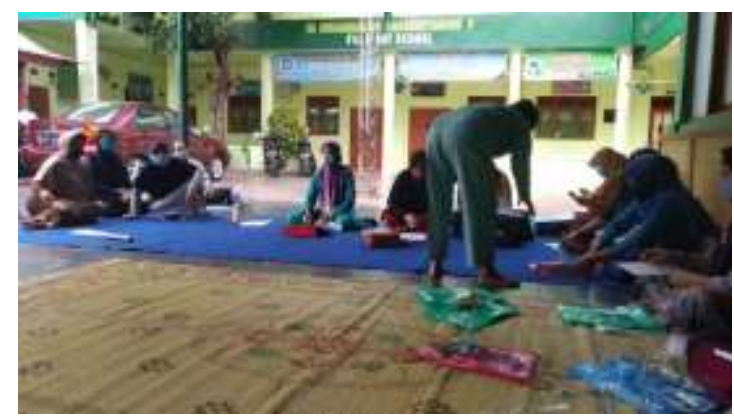

Gambar 1. Pembagian Face Shield dan Masker Kepada Peserta Pelatihan Sebelum Pelatihan

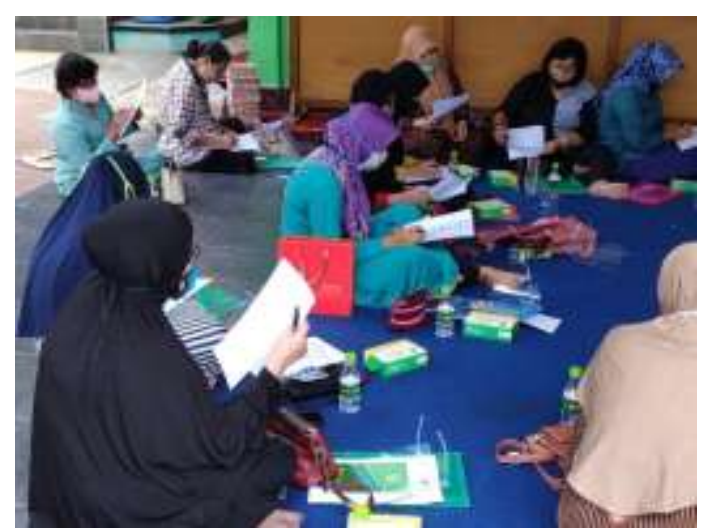

Gambar 2. Peserta Sedang Mengerjakan Pretest

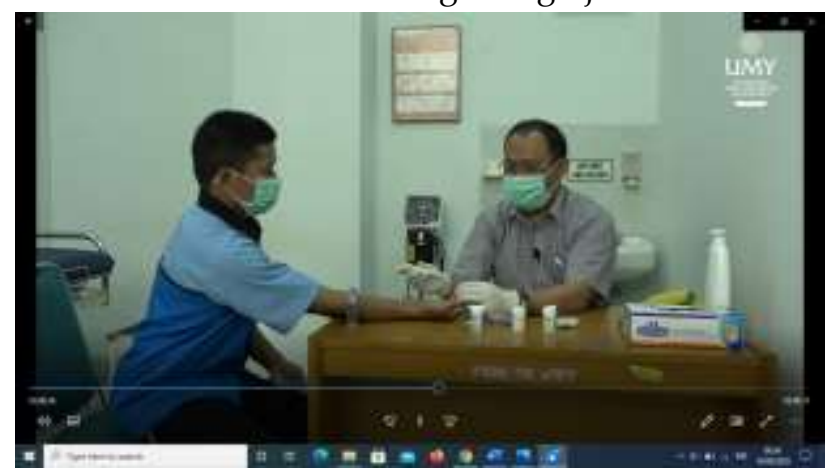

Gambar 3. Video Pemeriksaan Darah Sederhana untuk Skrining Penyakit Tidak Menular 


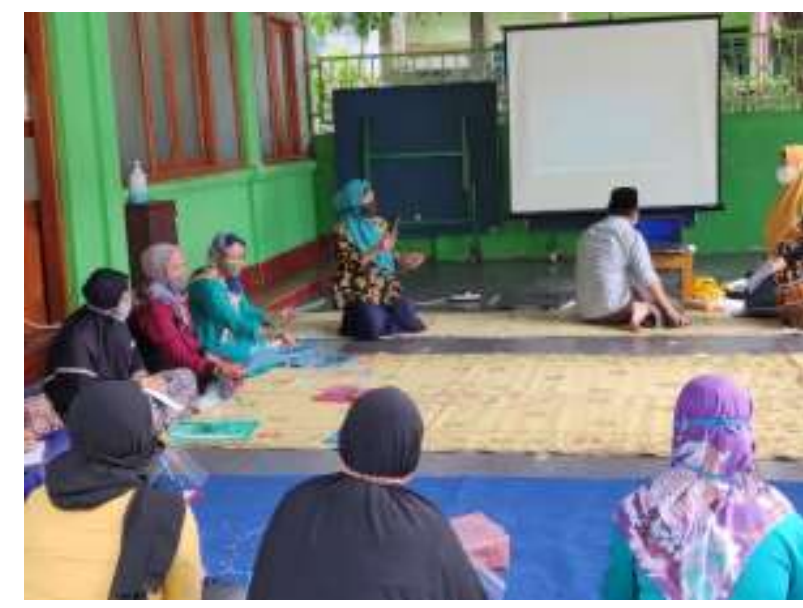

Gambar 4. Menghitung Kecukupan Gizi pada Menu Sehari-hari

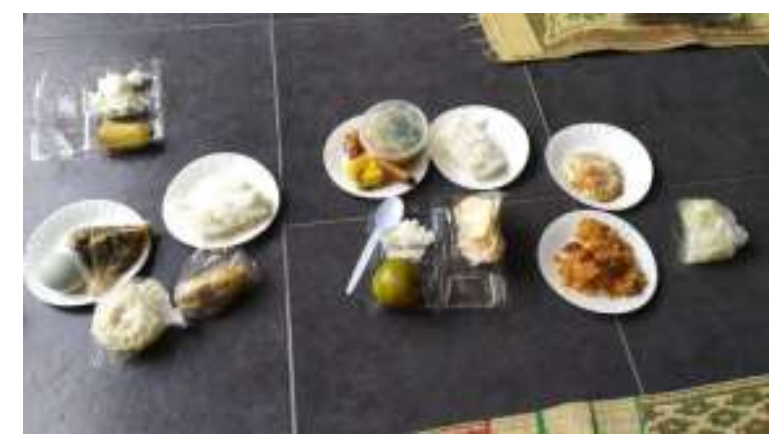

Gambar 5. Contoh Menu Sehari yang Dinilai Kecukupan Gizinya.

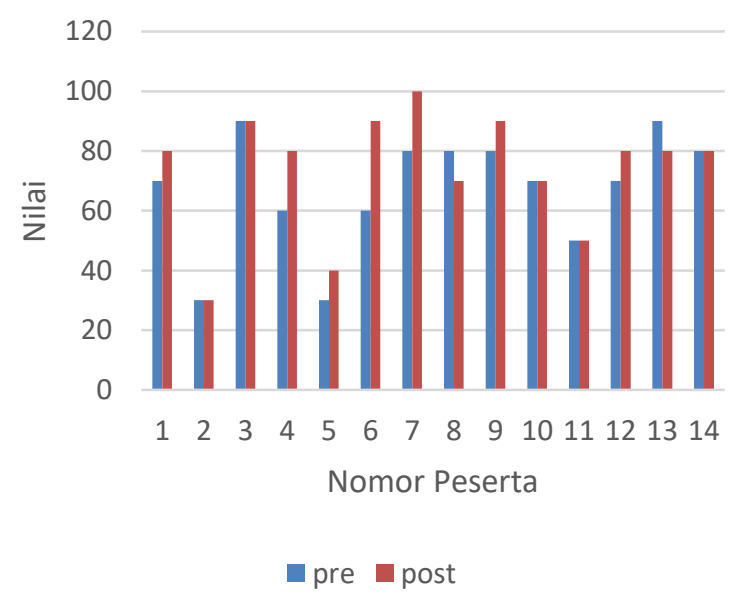

Gambar 6. Perbedaan nilai pretest dan postest tentang skrining PTM dan gizi seimbang

Sebagai evaluasi, sebelum dan sesudah pelatihan dilakukan test. Hasil rata-rata pretest 67,14 dan postest 73,57. Perbandingan skor pretest-postest disajikan pada Gambar 6. Tampak bahwa pengetahuan peserta mengenai PTM, gizi seimbang dan IMT sudah cukup baik dan setelah pelatihan terjadi peningkatan. Namun demikian pada analisis paired T-test menunjukkan tidak ada perbedaan bermakna antara sebelum dan sesudah pelatihan $(\mathrm{p}=0,076)$.

Evaluasi mengenai kecukupan gizi menunjukkan bahwa semua menu yang disajikan berlebih jumlah karbohidrat dan kurang serat serta protein. Asupan karbohidrat merupakan faktor dominan kadar gula darah (Werdani dan Triyanti, 2014; Yuniati et al, 2017), sedangkan asupan lemak dan serat tidak berhubungan dengan kadar gula darah (Yuniati et al, 2017). Kelebihan karbohidrat dalam jangka lama akan menyebabkan penyakit DM tipe 2. Diabetes mellitus tipe 2 diakibatkan oleh menurunnya aktivitas hormon insulin (resistensi insulin). Resistensi insulin dapat terjadi akibat faktor genetic, obesitas, dan penuaan (Fatimah, 2015) serta kurang aktivitas fisik dan kurang serat (Fitri dan Wirawanni, 2014; Santoso, 2011).

Diharapkan peningkatan pengetahuan dapat diikuti dengan perubahan perilaku cara hidup sehat. Perilaku merupakan faktor terbesar kedua yang mempengaruhi kesehatan manusia, baik secara individu, kelompok atau masyarakat (Blum, 1974 dalam Notoatmojo, 2007). Perilaku kesehatan adalah suatu respon seseorang terhadap stimulus atau objek yang berkaitan dengan sakit dan penyakit, sistem pelayanan kesehatan, makanan dan minuman serta lingkungan.

Beberapa PTM penting adalah penyakit kardiovaskuler, DM tipe 2, gangguan pernapasan kronis dan kanker (Warganegara dan Nur, 2016). Penyakit ini merupakan masalah kesehatan masyarakat di dunia termasuk Indonesia. Kematian manusia Indonesia akibat PTM semakin lama semakin meningkat. Terkait dengan pencegahan PTM di Indonesia, sejak 1992 paradigma kesehatan telah berubah dari kuratif menjadi promotif-preventif. Bahkan dengan adanya BPJS, masyarakat didorong untuk melakukan pencegahan mandiri. Hal ini perlu dapat diawali dengan meningkatkan pengetahuan. Pengetahuan merupakan domain yang sangat penting dalam membentuk tindakan seseorang (Notoatmodjo, 2007).

Kader kesehatan adalah tenaga yang berasal dari masyarakat, dipilih oleh masyarakat dan bekerja untuk masyarakat secara sukarela 
(Mantra, 1983). Mereka dilatih untuk menangani masalah-masalah kesehatan baik perseorangan maupun masyarakat serta bekerja dalam hubungan yang amat dekat dengan masyarakat di tempat pemberian pelayanan kesehatan (Posyandu) (Kemenkes RI, 2011). Dengan demikian diharapkan pengetahuan dan praktek yang diperoleh dari pelatihan dapat diterapkan melalui kegiatan posyandu dan PKK setempat. Apabila pemeriksaan darah rutin paling tidak satu tahun sekali dilakukan secara mandiri oleh masyarakat, maka diharapkan kasus PTM dapat lebih awal ditemukan sehingga dapat dicegah kasus fatal akibat PTM.

Untuk menjamin keberlanjutan, pengabdi memberikan sumbangan alat pemeriksaan darah sederhana, alat pengukur tinggi badan dan berat badan agar kader kesehatan dapat melakukan pemeriksaan secara mandiri rutin setahun sekali dan melaporkannya kepada petugas Puskesmas.

Agar kegiatan efektif sampai pada tujuan yaitu penderita PTM atau pra PTM tidak memberat atau fatal, maka direncanakan kegiatan PKM selanjutnya berupa pendampingan bagi penderita PTM atau pra PTM. Program pendampingan direncanakan akan melibatkan petugas Puskesmas atau Dokter Praktek Swasta yang memiliki Klinik Pratama. Hal ini seiring dengan Program Pencegahan dan Pengendalian faktor risiko PTM di Indonesia menurut Kemenkes RI, yaitu meliputi advokasi, kerjasama, bimbingan dan manajemen PTM; promosi, pencegahan, dan pengurangan faktor risiko PTM melalui pemberdayaan masyarakat; penguatan kapasitas dan kompetensi layanan kesehatan, serta kolaborasi sektor swasta dan professional; penguatan surveilans, pengawasan dan riset PTM.

\section{Ucapan Terima Kasih}

Ucapan terima kasih kami sampaikan kepada LP3M UMY yang telah memberikan dana untuk kegiatan PKM.

\section{KESIMPULAN DAN SARAN}

Kesimpulan

Tingkat pengetahuan tentang PTM dan pencegahannya sudah cukup baik di kalangan kader kesehatan di Dusun Gamping
Kidul dengan skor 67,14.

Pelatihan mengenai skrining PTM dan pencegahannya dapat meningkatkan pengetahuan tentang PTM dan pencegahannya, meskipun tidak signifikan dengan skor 73,57.

Saran

Selanjutnya diharapkan kader kesehatan dapat melakukan skrining PTM secara mandiri melalui Posyandu/ Posbindu. Ke depan perlu dirintis kerjasama dengan petugas Puskesmas dalam rangka menindak lanjuti penemuan pasien PTM hasil skrining mandiri tersebut.

\section{REFERENSI}

Cozma A., Adela ST, Laura U., Adriana F., Ramona S., Crina M., et al., 2018 "Unhealthy lifestyle and the risk of metabolic syndrome- the Romanian experience," J Mind Med Sci. 2018; 5(2): 218-229. doi: 10.22543/7674.52.P218229

Dinkes DIY, 2020. Profil Kesehatan DIY tahun 2019.

https://www.dinkes.jogjaprov.go.id

Fatimah RN. Diabetes Mellitus Tipe 2. J Majority, Februari 2015: 4(5):93-101

Fitri RI, dan Wirawanni Y. Hubungan Konsumsi Karbohidrat, Konsumsi Total Energi, Konsumsi Serat, Beban Glikemik dan Latihan Jasmani dengan Kadar Glukosa Darah pada Pasien Diabetes Mellitus Tipe 2. JNH, Juli 2014 : 2 (3): 1-27 Kementerian Kesehatan RI. Buku Panduan Kader Posyandu Menuju Keluarga Sadar Gizi Jakarta: Kemenkes RI; 2011

Mantra, I.B. 1983. Kader Tenaga Harapan Masyarakat. Proyek Pengembangan Penyuluhan Gizi. Jakarta: Departemen Kesehatan RI.

Michishita R, Matsuda T., Kawakami S., Kiyonaga A., Tanaka H., Morito, N., and Yasuki Higaki. The Association Between Unhealthy Lifestyle Behaviors and the Prevalence of Chronic Kidney Disease (CKD) in Middle-Aged and Older Men. J Epidemiol 2016;26(7):378-385

McPhee JS., French, DP., Jackson, D., Nazroo J., .Pendleton,N. Hans Degens Physical 
activity in older age: perspectives for healthy ageing and frailty. Biogerontology. 2016;17:567-580

Notoatmodjo, S. 2007. Promosi Kesehatan dan Ilmu Perilaku. Jakarta : Rineka Cipta.

Santoso, A. 2011. Serat Pangan (Dietary Fiber) dan Manfaatnya Bagi Kesehatan. Magistra. Maret 2011:75(XXIII): 35-40.

Werdani, AR., dan Triyanti, 2014. Asupan Karbohidrat sebagai Faktor Dominan yang Berhubungan dengan Kadar Gula Darah Puasa. Jurnal Kesehatan Masyarakat Nasional. Agustus 2014: 9(1): 71-77

WHO, World Health Organization Noncommunicable Diseases (NCD) Country Profiles, 2018: Indonesia. https://www.who.int/nmh/countries/ idn_en.pdf?ua $=1$

Wiranegara dan Nur, 2016. Faktor Risiko Perilaku Penyakit Tidak Menular. Majority | Volume 5 Nomor 2 April 2016. Pp 88-94

Yuniati R, Pradigdo SF, Rahfiludin MZ. Hubungan Konsumsi Karbohidrat, Lemak dan Serat dengan Kadar Glukosa Darah pada Lanjut Usia Wanita (Studi di Rumah Pelayanan Sosial Lanjut Usia Pucang Gading Kota Semarang Tahun 2017). Jurnal Kesehatan Masyarakat.

Oktober 2017:5(4): 759-767 